\title{
Nature and Function of Logic in African Epistemology
}

\author{
Dr. Ejikemeuwa J. O. Ndubisi \\ Department of Philosophy \& Religious Studies Tansian University, Umunya \\ Anambra State, Nigeria
}

\begin{abstract}
The burden of this paper is an investigation into the nature and functions of logic in African Epistemology. Epistemology inquires into the nature, possibility and veracity of human knowledge. It deals with the object and problems of human knowledge. Logic, on its part, distinguishes correct reasoning from incorrect reasoning. It borders on the criteria or the yardstick for our acclaimed knowledge. Logic and epistemology are among the essential or major branches of philosophy. Logic provides the necessary 'instruments' for proper presentation of what we claim to know. Employing the method of philosophical analysis, this paper states that logic is very essential to the study of African Epistemology. The paper therefore concludes, among other things, that the function of logic in African epistemology is to provide the African epistemologist with good, coherent and systematic approach to objective knowledge acquisition.
\end{abstract}

Keywords: Epistemology, Logic, human knowledge and systematic approach.

\section{Introduction}

Knowledge acquisition is central to the being of the human person. Every human person, whether young or old, desires to know. The quest for knowledge therefore is not the exclusive preserve of any group of people. It is something that characterizes our being human. In this regard Omoregbe as cited in Ozumba (2004:40) maintains that the human nature and experience are basically the same all over the world and that the tendency to philosophize is part of human nature. The implication of this assertion is that the capacity to acquire knowledge is innate in human beings. Every human person, regardless of colour, race, status, location, etc., has the potentiality to acquire knowledge.

In philosophy, Western or African, logic and epistemology are very fundamental. They constitute the major branches of philosophy. They are concerned with the object and method of human knowledge. Remove knowledge, human life would be meaningless; any neglect on logic makes a particular claim to knowledge questionable and difficult for general acceptance. One thing to note is that without logic in epistemology, true or valid knowledge may not be attained. Ozumba (2004:40) observed that every society has its own stock of epistemological thoughts, methods and world views. Since the quest for knowledge is part of human nature, there is no culture or tradition that is devoid of this essential quality. The African also has his own method or means of acquiring knowledge. The question now is: How logical are these African modes of acquiring knowledge? Put in another way: What is the role of logic in the African way of acquiring knowledge? The attempt to answer this question is the concern of this paper. Therefore, this paper takes a look at the understanding of the concepts: logic and African epistemology, the modes of acquiring knowledge in African epistemology, the functions of logic in African epistemology. It later ends with a concluding reflection.

\section{Logic: An Overview}

The art of sound, correct and critical reasoning is in the domain of logic. Logic concerns itself with the proper method of reasoning. It distinguishes correct reasoning from incorrect reasoning; removes ambiguities and obscurities from human discourse. Logic brings out truth from falsity, consistency from inconsistency, orderliness from disorder, valid argument from invalid argument. Logic dissipates confusion that usually arises in our everyday discourse. It is logic that differentiates rational beings from irrational beings. The proper application of logic is what separates human beings from the lower animals.

In the view of Bello (2000:1), logic is concerned with the study of the principles and techniques of distinguishing good arguments from bad argument. The implication of Bello's position is that logic has to do with the proper structures of thinking. It provides the platform for coherent thinking. Copi (1982:2) emphatically states that logic studies the method and principles by which we differentiate good reasoning from bad reasoning and correct reasoning from incorrect reasoning. Aja (2008:3) observed thus:

The basic aim of logic is to teach us to reason correctly. Reasoning is the activity or process of adducing, collecting reasons, weighing them, and drawing conclusions based upon these reasons. Correct reasoning is the art of finding reasons and/or evidence which do, in fact, support and/or prove our conclusion. 
The observation of Aja presupposes that without logic, correct reasoning will be impossible. More so, for any claim to be acceptable, there must be some convincing evidence to support the claim, otherwise, it may not be regarded as true knowledge. This is because of the simple fact that it lacks convincing justification. Echekwube (1999) as cited in Jaja and Badey (2012:96) noted that "logic ... is concerned with the processes of thinking and reasoning as well as the symbolic expressions of such process in verbal or written form." Logic also deals with the use of language for proper communication and comprehension. The inherent relationship between logic and language, in the view of Jaja and Badey, explains why logicians critically examine statements used in language to see if conclusions follow from the premise or premises (Jaja and Bradey, 2012:96). In sum, logic helps the individual to form arguments properly for better communication. It is logic that sharpens our thinking faculty and purifies the way we reason.

\section{African Epistemology}

The desire to know is innate in every human being. Every day, we make claim to certain knowledge. We even go as far as arguing for the thing that we claim to know. But some basic questions arise: What actually do we know? Is knowledge relative or objective? Can there be absolute claim to knowledge? What is the foundation for the knowledge we claim to have? The answers to the above questions form the subject matter of epistemology. Epistemology deals with the nature, origin and basis of human knowledge. Omoregbe (1998:vi) relates that epistemology as a major branch of philosophy is "the study of human knowledge, the study of the nature of human knowledge, its origin, its scope, its limits, its justification, its reliability or otherwise, its certainty or otherwise. It is like knowledge taking a critical look at itself to justify itself." In the view of Eboh (1998:1), epistemology simply deals with the justification of human knowledge. It examines the validity or truth of human knowledge (Eboh:1998:2). It is clear from the views of Omoregbe and Eboh that epistemology basically deals with justification of knowledge claim. So it is not enough for one to claim to know something; one has to show that what one claims to know is the case. For instance if I say that Prof. Oguejiofor is a Catholic priest or that Dr. Goodluck Ebele Jonathan is the current president of Nigeria, I have to present evidence to substantiate or justify the claim. If not, such a claim is nonsense and therefore should not be regarded as knowledge.

[A]ny claim to knowledge presupposes, if it is to be a valid claim, the satisfaction of conditions concerning grounds, truth, meaning and perhaps other things. To investigate these conditions is a philosophical task. To establish these general conditions is to elucidate the concept of knowledge, and this is a prime task of a philosopher concerned with the theory of knowledge [Epistemology]. (Hamlyn, 1977:5).

African epistemology is one of the major branches of African philosophy. We must note that African philosophy, in sum, has to do with a critical reflection on the African and the African world. Just like every other aspect of African philosophy, African epistemology has been observed to be in a bad state conceptually (Ozumba, 2004:35). The fact is that Africans have been regarded as those who do not reflect or reason but simply appeal to emotion. They are simply emotional beings rather than rational beings. It is against this misconception that Omoregbe (1985) as cited in Ozumba (2004:40) categorically stated that human nature and human experience are basically the same all over the world and the tendency to philosophize is part of human nature; all human beings reflect on some fundamental philosophic questions about life or about the universe. African epistemology therefore is the concretization of what is known in the African world. It is all about the way the African reflects on the reality within the African world. It also has to do with the ways and manners the African makes effort to justify what he claims to know. Aja in Uduigwomen (2002:36) pointed out that the problem of knowledge in traditional African thought is that of ascertaining whether or not what is claimed as knowledge is actually knowledge rather than mistaken opinion on the other hand, and the means or source of acquiring the knowledge on the other. In the view of Ozumba (2001:171), African epistemology has to do with Africa's own way of carrying out its enquiries into the nature, scope and limits of knowledge. Now the pertinent question is: What is that Africa's own way of knowledge acquisition? It is simply the mode or manner through which the African talks about reality in the African world. It must be observed that there are varied ways and means of knowledge acquisition in Africa. Let us now look at the forms of knowledge acquisition in African epistemology.

\section{Forms Of Knowledge In African Epistemology:}

There are varied forms of knowledge in African epistemology. They include: perceptual knowledge, common sense knowledge, old age knowledge, inferential knowledge, mystical knowledge, oral tradition, wholistic knowledge, etc. Let us briefly analyze them to enable us have a better understanding of ways and manners of knowledge acquisition in African epistemology. 


\section{Perceptual knowledge:}

As the name implies, this type of knowledge is gained through sense perception. It is called first-hand knowledge. The African person holds that knowledge is gained through what we see, hear, touch, taste or smell. This is embedded on the idea of 'afu n'anya e kwere' (to see is to believe). The idea that 'Mr. John is in the class' or that 'Snow is falling now' is within the domain of perceptual knowledge. The African finds it very difficult to doubt what he has witnessed with the empirical senses. The question of whether one is deceived by his senses is out place here. In some cases where there are problems of ascertaining the veracity of claim to knowledge, the African would ask for the eye-witness (the third party). But should the testimony of the eyewitness be doubted, oath-taking becomes the final reference point.

\section{Common sense knowledge:}

This is the type of knowledge that is gained effortlessly. It is the type of knowledge that is coeval with the human person. It is believed that every human person has this type of knowledge: the knowledge to distinguish between what is morally good or morally bad. It must be noted that the fact that every person possesses this type of knowledge is in kind and not in degree. The Igbo people would always say that 'Isi na isi ha bu n'onu' (That all heads are equal is just a matter of words of mouth). The implication here is that some people's common sense knowledge may be higher than others.

\section{Old Age Knowledge:}

This is the type of knowledge gained through wealth of experience. The Africans believe that the older a person is the more knowledgeable he/she becomes. It is also believed that the old person must have had series of experience in life which will now be the basis for most of his decisions. Also, in the African hierarchy of beings, there is the belief that the old people are closer to the gods who are the sources of all wisdom. So the ontological states of old people within the African world presuppose knowledgeability. A person is said to know or have wisdom in as much as he approaches divine wisdom. And a person approaches divine wisdom when he/she becomes less fleshy (Onyewuenyi, 1980:312). This simply means that the older a person gets, the more knowledgeable he is.

\section{Inferential Knowledge:}

Simply put, inference is the act of drawing conclusion from a given fact of data. So inferential knowledge is the type of knowledge gained from repeated events or phenomena. If a little child says the truth once, twice or trice, the African elder concludes that the little child is truthful. This type of knowledge / conclusion is amplified by the past experiences. However, there is a problem that goes with this form of knowledge which is not within the scope of this study. The important thing to note is that the African in his quest for knowledge tries to make reference to the past to enable him ascertain the present.

\section{Mystical Knowledge:}

This is the type of knowledge acquired through extra-ordinary means. It is beyond the ordinary sense perception. It is the type of knowledge gained through the help of the gods and other spiritual beings. It is a form of knowledge that is the exclusive preserve of some individuals. The African believes that those who are privileged to possess this type of knowledge are the diviners, priests, native-doctors, witches, rain-makers, etc. Uduigwomen (2002:38) observed that these set of people are believed to possess certain "innate abilities" that enable them to manipulate the spirit world in favour of the natural world. Ekarika (1984) argued that this type of knowledge has to do with obtaining information or truth about the past and the future things. Umontong (2002:34) also noted that among the Annang people of Nigeria, mystical knowledge is the major determinant of truth that is beyond ordinary man's understanding. One thing to note about this type of knowledge is that it is African's own way of gaining knowledge of realities that are ordinarily hidden.

\section{Oral Tradition:}

This is the form of knowledge gained through words of mouth. It is the major means of knowledge acquisition and transmission in the African traditional society. Oral tradition has to do with the accumulation of events handed down from one generation to the other in form of proverb, myths, stories, folk-tales, customs, legends, etc. Some of the things we claim to know today are the things handed down to us through oral tradition. This form of knowledge acquisition is very important to the African person. More so, this form of knowledge disposes the African child to fall in tune with the demands of his immediate society. Uduigwomen cited Ajayi's position on oral tradition as a source of knowledge in African epistemology. He noted that oral tradition are sometimes enshrined in the works of arts, crafts, symbols, titles, names of places, shrines and sacred places (Uduigwomen, 2002:39). 


\section{Wholistic Knowledge:}

It is the belief of the African person that knowledge of reality cannot be gained if the individual person detaches himself from it. This implies that knowledge of a given reality must involve the subject and the object, the knower and the known. This is what is known as wholistic knowledge in African epistemology. Anyanwu and Ruch (1981:94) declared thus: "The African maintained that there can be no knowledge of reality if an individual detaches himself from it." It therefore follow that there is a connection or a relationship that exists between the African person and his world. The African does not claim to know anything in isolation.

Having stated the forms of knowledge in African epistemology, we shall now look at the functions of logic in African epistemology.

\section{Functions Of Logic In African Epistemology}

Logic, as noted earlier, has to do with the structure of thinking. Every culture has its own method of reasoning. This is the sense in which we talk of African logic. Momoh (1989:174) writes:

In everyday usage of natural language we talk of a person as being logical if he is reasonable, sensible and intelligent; if he can unemotionally and critically evaluate evidence or a situation; if he can avoid contradictions, inconsistency and incoherence, or if he can hold a point of view argue for and from it, summon counter-examples and answer objections.

It is the view of Momoh as cited above that there are people who are logical in the sense stated above. Consequently, Africa is not an exception. Logic in African epistemology deals with the application of reason to the world and culture of the African, to his language and objects of his reference (Jaja \& Badey, 2012:97). For instance, when a bird cries at night and a person dies in the morning, the African elders conclude that the cry of the bird at night is the cause of the death in the morning. This type of conclusion was not reached after single occurrence; it was base on several cases of witnessing a particular birth crying at night and a person dying in the morning. The simple fact that the African did not just arrive at a conclusion after a single occurrence goes to show the logicality or rationality of the African person. However, our concern here is not on African logic per se, but on the functions of logic in knowledge acquisition in African epistemology.

The function of logic in knowledge acquisition is quite enormous. Without logic the study of African epistemology will be greatly impaired. There is this Igbo adage: "Ilu bu mmanu ndi Igbo ji eri okwu" (Proverb is the oil Igbo people use in 'eating' words). Put differently, we can say that logic is the key with which we use to unlock knowledge. The implication of this statement is that logic is very essential in epistemology whether African or Western. A person may claim to know something, but without the tools of logic, he may not be able to present his ideas very well. And when ideas are not properly presented, the particular claim to knowledge is inhibited. In a general sense, we can say that logic purifies our thinking pattern and makes us critical in our reasoning. More so, we affirm that without the application of logic in epistemology, true and certain knowledge may be very difficult if not impossible to attain. Let us now highlight the functions of logic in African epistemology:

\section{Avoidance of Error:}

Error simply means a departure from what is proper. It is an act of giving assent to a false claim. It also means a movement away from the truth. The study of logic therefore helps the African to stick to true knowledge and avoid accepting any knowledge that is erroneous. This can be ascertained by following the rules of logic. In African epistemology, logic guards the African against the habit of drawing conclusions from premises that are totally unrelated to the stated conclusion. This is one of the ways by which logic makes knowledge acquisition to be free from error.

\section{Correct / Sound Reasoning:}

Logic provides the African with the necessary tools to engage in correct and sound reasoning. It makes it possible for African epistemologist to be able to evaluate arguments in order to distinguish the correct one from the incorrect. The study of logic improves the reasoning capacity of the African person. Thus we can say that logic sharpens the thinking faculty of the African. The African person is not only an emotional being as argued in some quarters, but more so, a rational being. This is exemplified in his quest for evidence for any knowledge claim.

\section{Clarity of Expression:}

Some claims to knowledge are sometimes too blurred and confusing. Also, some ideas and expressions are often packaged in obscurity. A person may claim to know something but the illogical presentation can downplay his claim to knowledge, thereby creating confusion and making it very difficult for people to comprehend what is being said. It is the function of logic to sift out clarity in knowledge acquisition. Logic 
therefore provides African epistemology with the systematic and coherent ways of acquiring and expressing knowledge.

\section{Prediction of Event / Decision-Making:}

Another important function of logic in African epistemology is that it facilitates the act of prediction of events. With the help of logic, the African person, most especially the elderly, can predict events with a high level of accuracy. This is based on past experience. Logic enables the African to reason critically before taking decisions especially when faced with difficulties.

\section{The Power of Persuasion:}

Logic provides the African epistemologists with the necessary tools to be able to distinguish between persuasion based on certain psychological techniques and the one based on rational argument and supporting evidence.

\section{Avoidance of Fallacy:}

A fallacy is an argument whose conclusion is not derived from the premises given. Aja (2008:115) states that in logic "fallacious argument is one in which the premises, even if true, would never entail nor justify the premises that is drawn." With the study of logic, the African gets to know and learn the varied classes of fallacies. This provides the African with the ample opportunity to detect easily any violation of logical principle.

\section{Concluding Reflection:}

So far, this paper has concerned itself with the analysis of the nature and functions of logic in African epistemology. It emphasized that the African can possess no knowledge if the individual detaches himself from the world. This implies that knowledge acquisition in African epistemology is a combination / co-operation of all his faculties. His senses, imagination and reason are involved in the process of acquiring knowledge. It is through this way that the African can claim to have acquired knowledge. We therefore note that the general method by which the African arrives at a reliable knowledge of reality is through personal experience guided by logic. Logic plays a vital role in knowledge acquisition in African epistemology.

Going through this work, one will discover that logic is a conditio sine qua non for knowledge acquisition. Without logic the African person may not be balanced in his quest for knowledge. Therefore, we affirm that logic provides African epistemologist with the necessary tools to separate real knowledge from illusion; to sift correct reasoning from incorrect reasoning. The study of logic makes the African to be systematic, coherent and critical in his reasoning. Logic therefore provides the ground / foundation for accepting any claim to knowledge. It disposes the African epistemologist to ask for evidence before accepting any claim to knowledge. One important point to note is that the function of logic in African epistemology has to be viewed through the focal lens of the African person as a being in the African world.

\section{References}

[1]. Aja, E., Logic and Clear Thought: An Invitation to good reasoning $2^{\text {nd }}$ ed., (Enugu: University of Nigeria Press, 2008).

[2]. Anyanwu, K. C. \& Ruch, E. A., African Philosophy: An Introduction to the Main Philosophical Trends in Contemporary Africa (Rome: Catholic Book Agency - Officium Libri Catholic, 1981).

[3]. Bello, A. Introduction to Logic (Ibadan: University Press, 2000).

[4]. Copi, I. M, Introduction to Symbolic Logic (New York: Macmillan, 1982).

[5]. Eboh, B. O., Basic Issues in the Theory of Knowledge (Nsukka: Fulladu Publishing Company, 1995).

[6]. Ekarika, J. P., From Nature to Divine: An Introduction to the Study of Religions (Italy: 1984).

[7]. Hamlyn, D. W., The Theory of Knowledge, (London: The MacMillan Press Ltd., 1977).

[8]. Jaja, J. M. \& Badey, P.P., "Logic in African Philosophy: Examples from two Niger Delta Societies" International Journal of Academic Research in Business and Social Sciences, vol. 2. No. 4 (2012), Pp. 95 - 102.

[9]. Momoh, C. S. (ed.), The Substance of African Philosophy (Auchi: African Philosophy Projects Publications, 1989).

[10]. Omoregbe, J., Epistemology: A Systematic and Historical Study (Lagos: Joja Educational Research \& Publications Ltd., 1998).

[11]. Onyewuenyi, I., "Is There An African Philosophy?" in Claude Summer (ed.) African Philosophy, (Addis Ababa: Addis Ababa University Press, 1980).

[12]. Ozumba, G. O. A Concise Introduction to Epistemology (Calabar: Ebeneger Printing Press, 2001).

[13]. Ozumba, G. O., A Colloquium on African Philosophy, vol. 2 (Enugu: University of Nigeria Press, 2004).

[14]. Uduigwomen, A. F. (ed.), Footmarks on African Philosophy, (Lagos: Obaroh and Ogbinaka Publishers Ltd., 2002).

[15]. Umontong, I. D., "Truth: A Philosophical Reflection on Africa", Sophia: African Journal of Philosophy, vol 2. No. 2 (2002), pp 25 -39 . 